Editorial

\title{
The Journal of Risk and Financial Management in Open Access
}

\section{Michael McAleer ${ }^{1,2}$}

1 Department of Quantitative Finance, National Tsing Hua University, Hsinchu, Taiwan

2 Econometric Institute, Erasmus School of Economics, Erasmus University Rotterdam, Rotterdam, The Netherlands; E-Mail: michael.mcaleer@gmail.com

Received: 19 September 2013 / Accepted: 20 September 2013 / Published: 1 October 2013

\section{Introduction}

Financial economics and econometrics have advanced rapidly in recent years, in terms of coverage of topics, the creation of new data sources, the availability of existing high frequency and ultra-high frequency tick data, the growing importance of international financial analysis, the technicality of research topics, and the number of papers and journals publishing such theoretical and practical research.

The recognition of high quality work in the field is rapid, due to the immediate applicability of much of the research undertaken in the field. This is reflected, for example, in frequent citations of recent works.

Established five years ago, the Journal of Risk and Financial Management (JRFM) is an international journal with the goal of advancing knowledge and understanding in the practice of risk management and financial management, through the publication of high quality papers that are relevant to practitioners in the field.

\section{Journal Scope}

The journal offers a specialized forum for applied research on financial management and risk management that includes but is not restricted to:

- credit and investment risk;

- econometric and statistical analysis of high frequency and ultra-high frequency financial data;

- investing in financial markets, financial derivatives and instruments;

- financial market regulation;

- monitoring and regulation of risk;

- optimal hedging strategies for large portfolios of assets; 
- risk management processes;

- risk and volatility modeling;

- risk and performance management and measurement;

- time series and cross-section financial data;

- univariate and multivariate models of risk.

JRFM serves as a bridge between academic research and practice by seeking academically rigorous papers that have direct relevance to practitioners, and acting as a forum for presenting the perspectives of practitioners, academics and regulators regarding financial management and risk management and their applications.

\section{Submissions}

Manuscripts submitted to JRFM for possible publication should be based on sound risk and financial management theory. Technically sound and well-supported research based on econometric and statistical methods in specification, estimation, testing, evaluation, and forecasting for specific applications is encouraged. Papers that use quantitative, econometric, and statistical methodologyespecially where there is scope for immediate application - are of especial interest.

\section{Multidisciplinary Digital Publishing Institute (MDPI) and Open Access Publishing}

Since its establishment in 1996, the Multidisciplinary Digital Publishing Institute (MDPI) has evolved to become a professional publishing house of Open Access journals, covering diverse subjects that include basic and applied research in the natural and social sciences. The website, www.mdpi.com, is a platform for peer-reviewed, scientific open-access journals operated by MDPI AG, based in Basel, Switzerland. All MDPI journals maintain a rapid, yet rigorous, peer-review, manuscript handling, and editorial process.

MDPI has kindly agreed to upload the back issues of the JRFM onto its platform and to register a DOI number for each paper that was previously published in the journal. The move to the publication platform of MDPI will also ensure digital archiving of the back issues with CLOCKSS (http://www.clockss.org/) and the Swiss National Library digital archive (http://www.ehelvetica.nb.admin.ch/) to sustain the long-term access of the valuable contributions published in this journal.

MDPI aims to have all of its journals covered by the Science Citation Index Expanded (SCIE) and Scopus indexing systems. All MDPI journals are archived with the Swiss National Library. All MDPI journals are fully open access, so that research articles, reviews, and other content are available free of charge (open access publications are financed through article processing charges).

\section{Mission Statement and Acknowledgements}

It is a challenge, an honor, and a pleasure to be appointed the Editor-in-Chief of the Journal of Risk and Financial Management. I look forward to working with the members of the Advisory Board and Editorial Board, contributors and reviewers to make JRFM an accessible outlet for high quality academic and practical research in all areas of risk and financial management. 
The success of the journal since its inception would not have been possible without the substantial and sustained efforts of the Founding Editor-in-Chief, Professor Raymond A.K. Cox, and the Editors, Professors Alain Bensoussan, Da-Hsiang Donald Lien, and Wing-Keung Wong. I am delighted that their significant contributions to the journal will continue as highly valued members of the Advisory Board.

\section{Acknowledgments}

The author is most grateful to Alistair Freeland and his excellent team at MDPI for establishing the webpage of the journal, including uploading the first five years of published papers, and wishes to acknowledge the financial support of the Australian Research Council and the National Science Council, Taiwan.

(C) 2013 by the authors licensee MDPI, Basel, Switzerland. This article is an open access article distributed under the terms and conditions of the Creative Commons Attribution license (http://creativecommons.org/licenses/by/3.0/). 